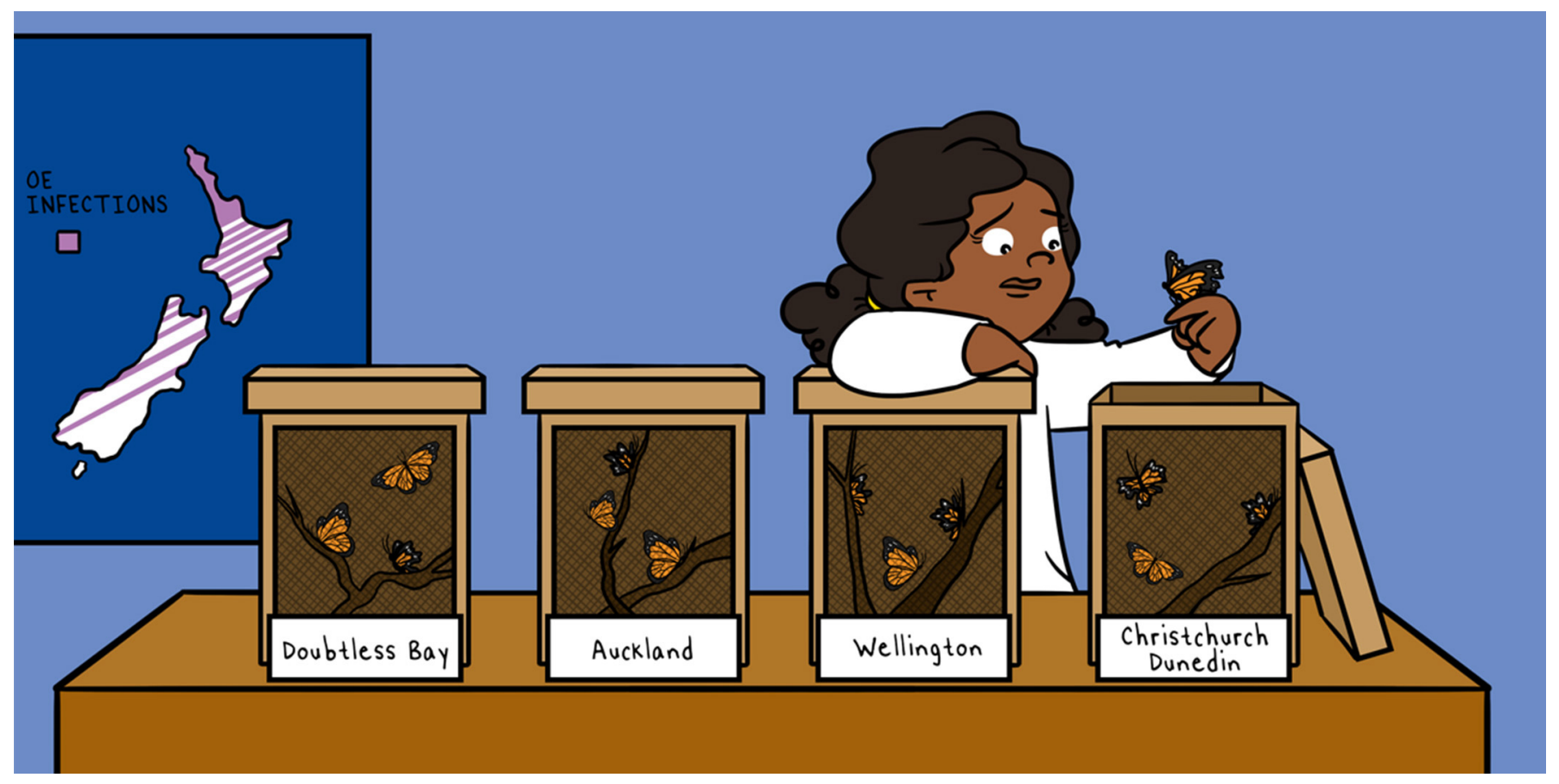

\title{
WING DEFORMITIES IN MONARCH BUTTERFLIES IN NEW ZEALAND: THE ROLE OF A PARASITE AND THE CLIMATE
}

\section{Mariana Bulgarella * and Philip J. Lester}

School of Biological Sciences, Victoria University of Wellington, Wellington, New Zealand

YOUNG REVIEWERS:

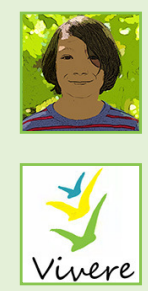

OWEN

AGE: 9

VIVERE

AGES: $11-12$

Monarch butterflies can be infected by a parasite called OE. Butterflies with OE may not complete their development or, if they do, the adult butterflies might have deformed wings. We found that the proportion of adult butterflies with wing deformities increased further south in New Zealand, where the weather is colder. In contrast, the number of butterflies infected with the OE parasite decreased further to the south. No OE was observed in butterflies from the coldest, southernmost location of Dunedin, while all butterfly samples from the warmest, northernmost site at the top of the North Island were infected. The OE parasite seems to vary on a north-south gradient, with more OE in the north and less in the south. Our analysis showed that being parasitised by OE did not mean butterflies were more likely to have wing deformities. We think that the colder temperatures in the south of the country limit the development of the OE parasite and independently cause the wing deformities seen in the adult butterflies. 
Figure 1

Butterflies are diverse and often abundant in tropical ecosystems. They can play a major role in pollination of plants. (A) Eastern tiger swallowtail, St. Paul, Minnesota, USA. (B) Julia butterflies, Iguazu Falls, Misiones, Argentina. (C) White-edged longwing butterfly, Guayaquil, Ecuador. (D) Postman butterfly, Guayaquil, Ecuador [Photograph credit: (A,B) Mariana Bulgarella; $(C, D)$ Gabriel A. Brito-Vera].

\section{CHRYSALIS}

The pupa or third stage of a butterfly's development, during which the caterpillar transforms into an adult. The pupa is protected by a hardened outer shell.

\section{DIVERSITY}

A measurement of both the number of species within a community and the relative importance of each species.

\section{CITIZEN SCIENCE}

Scientific research in which members of the public volunteer to help collect data and sometimes even help analyse and report the data.

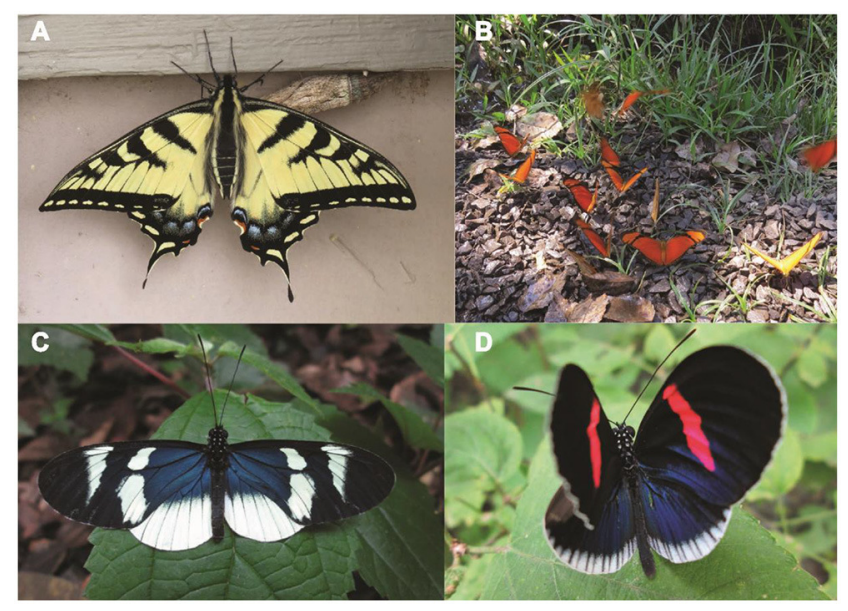

Figure 1

\section{WHAT IS A BUTTERFLY?}

You are probably familiar with the adult form of butterflies - the insects that visit flowers, are brightly coloured, and have a distinctive fluttery flight. Butterflies, like all insects, have six legs and three body parts (head, thorax, and abdomen), but butterflies and moths are the only insects with scales covering their wings. The life cycle starts when an adult butterfly lays an egg on the plant on which the caterpillar will feed. Caterpillars need to eat a lot of plant material to grow quickly. Next, the caterpillar turns into a chrysalis, which is the pupal stage of butterflies. From the chrysalis emerges an adult butterfly.

There are $\sim 17,500$ species of butterflies worldwide. Butterflies are diverse and often beautiful. Some of them have stunning wing patterns. Figure 1 shows some examples of butterfly species. These four butterflies are just a small representation of the diversity of butterflies and wing colours and patterns you can find in nature. Butterflies can play a major role in the pollination of plants.

\section{WHICH BUTTERFLIES WERE STUDIED?}

We studied a single butterfly species - the monarch butterfly that you have likely seen in your garden or local park. Monarch butterflies are easily recognised by their striking orange, black, and white markings. In New Zealand, they are the only type of butterfly with this colouration. They are also one of the butterflies we know more about because of their famous long-distance migration, from North America to Mexico. Citizen science has had a long history in deciphering the migration of these butterflies [1]. Citizen scientists are volunteers who contribute to scientific projects, usually by collecting or sometimes even analysing and reporting data. We also asked for the help of citizen scientists for our study. 
Figure 2

(A) Male monarch butterflies have black spots on their hind wings (red circle). (B) Female monarchs lack the black spots on their hind wings

(Photograph credit: Mariana Bulgarella).

\section{PARASITE}

An organism that lives on or inside a host organism and gets its food from or at the expense of its host.

\section{SPORE}

A reproductive cell capable of developing into a new individual in plants, fungi, certain algae, and protozoa.

\section{MIGRATE}

To periodically travel long distances from one region or habitat to another, according to the seasons.

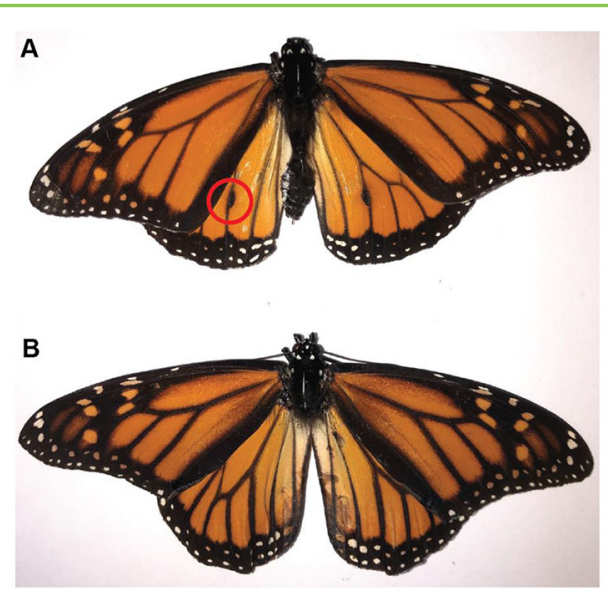

Figure 2

Monarch caterpillars feed only on swan plants, which are also called milkweed plants. These plants are poisonous to most vertebrates (animals with backbones) but do not hurt the monarch caterpillar. Feeding on swan plants makes the caterpillar poisonous to potential predators, giving it an advantage. Adult monarch butterflies feed on the nectar from flowers, which contains sugars and other nutrients. Monarchs will visit many flowers in their search for food. You can distinguish a male monarch from a female monarch easily, as the males have a black spot on a vein on each hind wing that is not present on the females (Figures 2A,B).

Monarch butterflies can carry a parasite called OE because it is much easier to say than its scientific name. OE can harm butterflies by reducing survival, weight, mating and flight abilities, and adult lifespan [2]. Heavy OE infections can result in butterflies that do not complete their development, or adult butterflies with wing deformities (Figure 3A). If a butterfly's wings are deformed, it cannot fly to feed on flowers or to find a mate, and it will probably die. Some scientists believe that $\mathrm{OE}$ is involved in the decline of monarch butterfly populations seen in the USA and other countries. The OE life cycle starts when an infected adult monarch, which harbours a huge number of microscopic OE spores on the outside of its body, scatters the spores onto monarch eggs or swan plant leaves. When a monarch caterpillar consumes the swan leaves with OE spores on them, the spores break open and the parasite grows and multiplies inside the caterpillar. The adult butterfly then emerges with a new generation of parasite spores on the outside of its body.

Monarch butterflies present in New Zealand do not migrate, and they occupy much of the country from the northernmost to the southernmost localities. This large distribution means that different populations of butterflies experience very different temperatures and growing conditions. 
Figure 3

Map of New Zealand showing where samples were collected (black dots). Data were grouped into four regions from north to south (black ovals). The graph on the left shows the percentage of butterflies with deformed or normal wings in each region. The graph on the right shows the percentage of butterflies infected with OE or uninfected in each region. (A) A butterfly with deformed wings. (B) A butterfly with normal wings. (C) Sample of butterfly scales and OE spores (circled in yellow), meaning an infection. (D) Sample of butterfly scales without $O E$ spores, no infection (Photograph credit: Phil Lester).

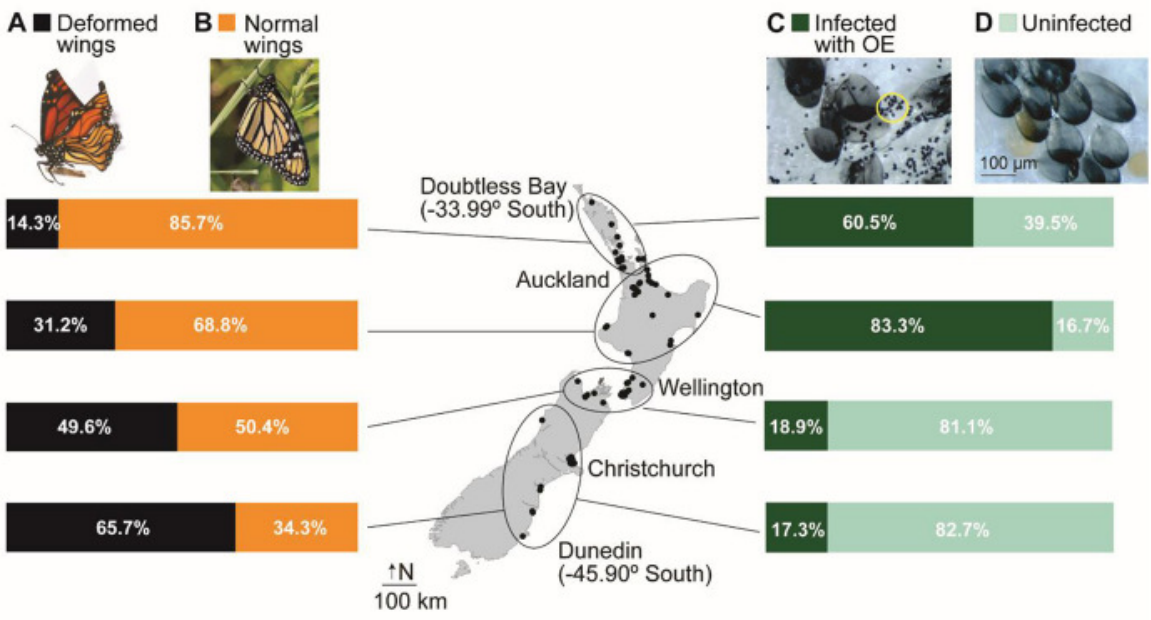

Figure 3

\section{WHAT DID WE STUDY?}

We studied the monarch butterflies of New Zealand to determine how many of them carry the OE parasite. After observing many adult monarch butterflies displaying wing deformities in our own gardens during the Southern Hemisphere autumn of 2020, we asked citizen scientists for monarch butterfly samples from throughout New Zealand.

We asked people to take samples from any adult monarch butterflies present in their gardens. There is an easy and harmless way to sample OE that involves placing clear, sticky tape on the adult butterfly's abdomen. A combination of butterfly scales and distinctive parasite spores stick to the tape (Figures 3C,D). The OE spores can only be seen under a microscope with high magnification. People attached the tape to a piece of white paper and mailed it to our university, along with information such as the condition of the butterfly wings (normal or deformed), the butterfly sex (female or male), and where in New Zealand the sample was collected.

Our request took place during the lockdown period for New Zealand during the COVID-19 pandemic. Individuals and families aged 4-86 sent us samples. We wanted to determine if butterflies parasitized by OE have more wing deformities and whether the relationship between the monarch butterflies and OE varies with the different temperatures they encounter across New Zealand.

\section{WHAT DID WE FIND?}

We received 559 good samples of adult butterflies, from the far north in New Zealand to the southernmost cities. Out of these samples, $58.9 \%$ (329) were infected with OE spores, and $40 \%$ of all butterflies 
had deformed wings. No OE spores were observed in samples from our southernmost (and coldest) locality of Dunedin, while all butterfly samples from the northernmost (and warmest) site of Doubtless Bay were infected with OE.

To our surprise, very few butterflies had deformed wings in the warmest, northernmost localities, but almost all butterflies from the north part of the country carried the OE parasite (Figure 3). Our statistical analysis showed that being parasitised by OE did not mean butterflies were more likely to have wing deformities. We think that cold temperatures influence both the development of butterfly wings and the development of the OE parasite. OE may not tolerate cold conditions. The wings of butterflies are more likely to be damaged during development in cold temperatures. In other regions of the world, parasites similar to OE also declined significantly in diversity and abundance with increasing latitude (colder temperatures).

\section{WHY IS THIS RESEARCH IMPORTANT?}

Some monarch butterfly populations are threatened due to a variety of factors. For example, climate change may result in the freezing of butterfly populations [3, 4]. Loss of habitat, diseases, and the use of insecticides in agriculture all appear to affect monarch butterflies. One research group found that the temperatures during the breeding season are especially important determinants of annual variation in the abundance of monarch butterflies [5]. Our results suggest that disease and climate might affect the butterflies differently at different latitudes. Future approaches to monarch conservation may need to be specific for the region where the butterflies occur, to account for interacting factors such as parasite-climate interactions.

The OE parasite is only known to infect monarch butterflies. However, spores from parasites related to OE can affect other butterflies and moths. Spores from species related to OE were found in three moth species (the cotton bollworm moth, the oriental tobacco budworm, and the Australian bollworm) and in one butterfly species (the New Guinea clipper) [6]. Therefore, the more we know about these parasites (their life cycles, how they infect butterflies and moths, how they live through the winter, etc.), the more we will be able to do to help butterflies thrive.

The results of our work further highlight the benefits and value of citizen science in understanding monarch butterfly biology and behaviour [7]. Our study makes it clear that data collected by citizen scientists can transform our understanding of an organism's biology, distribution, and diversity [8]. This is true not only for monarchs but also for many species of plants and animals. The next time you hear about a scientific project near you, join in! 


\section{ACKNOWLEDGEMENTS}

We are extremely grateful to the passionate and enthusiastic people who submitted samples from butterflies. We could not have done this work without you. Thanks to Gabriel Brito-Vera for sharing his butterfly photographs. Special thanks to the young reviewers and mentors for their fabulous comments that greatly improved the manuscript.

\section{ORIGINAL SOURCE ARTICLE}

Lester, P. J., and Bulgarella, M. 2021. A citizen science project reveals contrasting latitudinal gradients of wing deformity and parasite infection of monarch butterflies in New Zealand. Ecol. Entomol. 46:1128-35. doi: 10.1111/een.13057

\section{REFERENCES}

1. Urquhart, F. A. 1976. Found at last: the monarch's winter home. Natl. Geogr. 150:160-73.

2. de Roode, J. C., Altizer, S., and Hunter, M. D. 2019. "Multi-trophic interactions and migration behaviour determine the ecology and evolution of parasite infection in monarch butterflies," in Wildlife Disease Ecology: Linking Theory to Data and Application, eds K. Wilson, A. Fenton, and D. M. Tompkins (Cambridge: Cambridge University Press). p. 480-510. doi: 10.1017/9781316479964.017

3. Nail, K. R., Drizd, L., and Voorhies, K. J. 2019. Butterflies across the globe: a synthesis of the current status and characteristics of monarch (Danaus plexippus) populations worldwide. Front. Ecol. Evol. 7:362. doi: 10.3389/fevo. 2019.00362

4. Pennisi, E. 2021. Are monarchs in trouble? Science. 371:219-20. doi: 10.1126/ science.371.6526.219

5. Thogmartin, W. E., Wiederholt, R., Oberhauser, K., Drum, R. G., Diffendorfer, J. E., Altizer, S., et al. 2017. Monarch butterfly population decline in North America: identifying the threatening processes. R. Soc. Open Sci. 4:170760. doi: 10.1098/ rsos. 170760

6. Gao, K., Muijderman, D., Nichols, S., Heckel, D. G., Wang, P., Zalucki, M. P., et al. 2020. Parasite-host specificity: a cross-infection study of the parasite Ophryocystis elektroscirrha. J. Invertebr Pathol. 170:107328. doi: 10.1016/ j.jip.2020.107328

7. Ries, L., and Oberhauser, K. 2015. A citizen army for science: quantifying the contributions of citizen scientists to our understanding of monarch butterfly biology. BioScience. 65:419-430. doi: 10.1093/biosci/biv011

8. Soroye, P., Ahmed, N., and Kerr, J. T. 2018. Opportunistic citizen science data transform understanding of species distributions, phenology, and diversity gradients for global change research. Glob. Change Biol. 24:5281-91. doi: $10.1111 / g c b .14358$

SUBMITTED: 24 June 2021; ACCEPTED: 13 January 2022;

PUBLISHED ONLINE: 04 February 2022. 
EDITOR: Michel Edmond Ghanem, Mohammed VI Polytechnic University, Morocco

\section{SCIENCE MENTORS: Gustavo Fonseca and Kristen Welsh}

CITATION: Bulgarella M and Lester PJ (2022) Wing Deformities in Monarch Butterflies in New Zealand: The Role of a Parasite and the Climate. Front. Young Minds 10:729916. doi: 10.3389/frym.2022.729916

CONFLICT OF INTEREST: The authors declare that the research was conducted in the absence of any commercial or financial relationships that could be construed as a potential conflict of interest.

COPYRIGHT @ 2022 Bulgarella and Lester. This is an open-access article distributed under the terms of the Creative Commons Attribution License (CC BY). The use, distribution or reproduction in other forums is permitted, provided the original author(s) and the copyright owner(s) are credited and that the original publication in this journal is cited, in accordance with accepted academic practice. No use, distribution or reproduction is permitted which does not comply with these terms.

\section{YOUNG REVIEWERS}

\section{OWEN, AGE: 9}

I am 9 years old, and I love bees and chicken. In fact, I keep them as pets! One of my favorite things to do is to read. I also love science and gardening. I am interested in growing carnivorous plants and mushrooms.

\section{VIVERE, AGE: 11-12}

We are a group students in the 6th grade interested in environmental issues.

\section{AUTHORS}
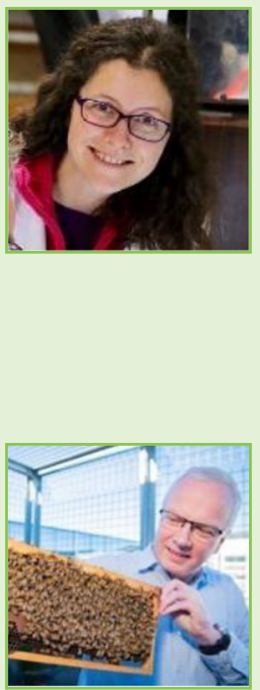

\section{MARIANA BULGARELLA}

Mariana Bulgarella is a research fellow at Victoria University of Wellington, in New Zealand. Mariana has research backgrounds in ornithology and entomology. She studies several aspects of insect biology, such as population genetics, their parasites, and diseases. She searches for potential management options for invasive insect species, to benefit both the biodiversity and the people. Two wasp invasions, the European paper wasp in New Zealand and the yellow paper wasp in the Galápagos Islands, are the focus of her current studies. *Mariana.Bulgarella@vuw.ac.nz

\section{PHILIP J. LESTER}

Phil Lester is an entomologist and ecologist, also at Victoria University of Wellington. Phil's work seeks to understand and manipulate factors that regulate populations. He works with social insects (ants, bees, and wasps). What roles do viruses, other pathogens, and parasites play in limiting insects' abundance? How can we reduce 
the effects of parasites and pathogens on some species, such as monarch butterflies and honeybees? When are parasites and pathogens useful for biological control of pests? 